\title{
Lipid lowering effect of synthetic phenolic compound in a high- fat diet (HFD) induced hyperlipidemic mice
}

Sadaf Nawaz ${ }^{1}$, Munazza shareef ${ }^{2,}$ Hina shahid ${ }^{1}$, Misbah Mushtaq ${ }^{1}$, Sanaullah Sajid ${ }^{3}$, Maliha sarfraz $^{2 *}$

${ }^{1}$ Department of pharmacy, University of Lahore, 38040, Pakistan

Institute of Pharmacy, Physiology \& Pharmacology,University of Agriculture, 38040 Faisalabad, Pakistan

${ }^{3}$ Institute of Microbiology, Faculty of veterinary science, University of Agriculture, Faisalabad, Pakistan

This is an open access article distributed under the Creative Commons Attribution License, which permits unrestricted use, distribution, and reproduction in any medium, provided the original work is properly cited.

\section{ARTICLE DETAILS}

Article history:

Received 22 January 2017

Accepted 03 February 2017

Available online 05 February 2017

Keywords:

\begin{abstract}
Hyperlipidemia is the major risk factor of arteriosclerosis, coronary heart diseases and death. Phenolic compounds have been shown to offer the protection against cardiovascular complications. In the present study, we studied the effect of semisynthetic phenolic compounds on the hyperlipidemic mice fed with high fat diet (cholesterol, cholic acid and peanut oil). Phenolic compounds were mixed with HFD and the dose of the test compounds were $10 \mathrm{mg} / \mathrm{kg}$ for 6 weeks. After 6 weeks, the average body weight of lab diet, HFD, standard and test compounds were evaluated. Average body weight of test compound 1, test compound 2 and test compound 3 showed insignificant results ( $P>1$ ) as compared to the standard drug (Atorvastatin in this study). The liver weight of mice increased (P>1) in all treatment groups relative to standard drug fed group. The plasma lipids such as triglyceride and LDL-cholesterol were found to be increased $(P>1)$ in Test compound 1, test compound 2 , test compound 3 and HFD fed mice when compared to that of standard drug (Atorvastatin) fed mice. But high-density lipoprotein (HDL) cholesterol increased in standard when compared to that of lab diet fed mice, HFD and test compounds. In conclusion, the supplementation of semi synthetic phenolic compounds may have a weak potential of hypolipidemic effect on mice fed high-fat diet.
\end{abstract}

\section{Introduction}

It is seen that most of the deaths are occurring due to diseases of cardiovascular system. There is a significant impact of lifestyle changes on the quality of health. Utilization of food highly rich with saturated fat and having low fiber content is one of the factors of disarray in energy balance. It is now evinced that hyperlipidemia is depicted as a major risk factor for the premature development of atherosclerosis and its cardiovascular complications. The prevalence of obesity has doubled in the past 25 years; today, twothirds of adults are overweight in the United State [1] Hyperlipidemia is a disorder characterized by the increase in blood lowdensity lipoprotein (LDL), total cholesterol (TC) and triglycerides (TG).More than 3 million people have this genetic disorder in the United States and Europe. This condition is an indicator of both coronary artery disease and atherosclerosis and is the main cause of cardiovascular disease worldwide. An accepted mean of treating the patients with hyperlipoproteinemia and atherosclerosis is lowering the serum triglycerides (TG) and increasing high-density lipoproteins (HDL) [2]

\section{Material and Method}

\subsection{Materials}

Normal lab diet, high fat diet including cholesterol, cholic acid, peanut oil, standard drug (Atorvastatin in this study), test compound 1, test compound 2 and test compound 3.

\subsection{Methods}

\subsubsection{Animals}

36 mice (5-week-old female) were obtained, kept in National Institute of Health and left to be acclimatized for 1 week before the experiment started. A total of 36 mice were divided into 6 experimental groups with each 6 mice per treatment group. Animals were kept in normal laboratory conditions of temperature $23 \pm 1{ }^{\circ} \mathrm{C}$ and ambient humidity $55 \pm 5 \%$. Mice were housed in stainless steel cages individually and kept in an isolated room. Lights were maintained on an artificial $12 \mathrm{~h}$ light-dark cycle. . All mice were weighed weekly during 6 weeks of experimental period Animal cares was in accordance to the guidelines established and approved by the National institute of Health

\subsubsection{Diets}

All diets were based on National Institute of Health (NIH) recommendations Mice were fed with high fat diet containing cholesterol, cholic acid, peanut oil and normal laboratory diet for 6 weeks. Standard drug (Atorvastatin in this study), Test compound 1 , test compound 2 and test compound 3 was mixed with high-fat diet (HFD) and the composition of the test compounds was $10 \mathrm{mg} / \mathrm{kg}$.

\subsubsection{Procedure for Antihyperlipidemic activity}

A total of 36 mice were divided into 6 experimental groups with each 6 mice per treatment group. Test compound 1, test compound 2 and test compound 3 was mixed with high-fat diet (HFD) and the dose f the test compounds were $10 \mathrm{mg} / \mathrm{kg}$. Group I received Normal laboratory diet, Group II received high-fat diet, Group III received standard drug (atorvastatin in this study) along with high-fat diet, Group IV received test 18 compound 1 along received with high-fat diet, Group V received diet test compound 2 along with high fat diet and Group VI received test compound 3 along with high fat diet. Mice had free access to feed and water throughout the study. The specified quantity of test compound and standard was dissolved in $1 \mathrm{~mL}$ of DMSO and mixed with water supplied to mice. All mice were weighed weekly during 6 weeks of experimental period. The activity was continued for 6 weeks under controlled laboratory conditions (temperature $23 \pm 1^{\circ} \mathrm{C}$ and ambient humidity $55 \pm 5 \%$ ).

\subsubsection{Blood collection and analysis}

At the end of the experimental period, the animals were anesthetized. Blood samples were collected from the retro orbital vein. The serum was separated by centrifugation at $2500 \times \mathrm{g}$ for $15 \mathrm{~min}$ at 4 2. The amount of serum triglyceride, total cholesterol, HDL- cholesterol, and LDL-cholesterol were assayed automatically using an ADVIA 1650 lipid analyzer (Bayer, Wuppertal, Germany)

\subsubsection{Statistical analysis}

For determination of change of body weight, liver weight, plasma lipids, HDL and LDLcholesterol, individual mouse was considered as an experimental unit. All data were analyzed by SPSS software general linear model procedure was performed and mean values and standard error were reported.

\subsubsection{Results and discussion}

Hyperlipidemia is one of the greatest risks of developing cardiovascular disorders and complications. It is characterized by increase in low density lipoprotein, total cholesterol and triglycerides. Natural phenolic compounds have been reported to show protection against atherosclerosis and metabolic disorders like hyperlipidemia, hyper glycaemia, and hypercholesterolemia. A study was conducted on catechin compounds derived from green tea; mice were fed a diet high in cholesterol and fat, after 4 weeks of treatment 
the rate of cholesterol absorption, total cholesterol low-density lipoprotein plasma levels were measured. Catechin compounds have been shown to reduce plasma cholesterol levels significantly in the group fed with these compounds. This study showed significant results [3] The present study is aimed to check the lipid lowering effect of synthetic phenolic compound in ah high- fat diet (HFD) induced hyperlipidemic mice. Effect of phenolic compounds on biochemical parameters including serum total cholesterol (TC), triglycerides (TG), high-density lipoprotein (HDL), and low-density lipoprotein (LDL) will be estimated in HFD induced hyperlipidemic mice. The results obtained are then compared with the effects of marketed product Atorvastatin. 36 mice (5-week-old female) were obtained and left to be acclimatized for 1 week before the experiment started. A total of 36 mice were divided into 6 experimental groups with each 6 mice per treatment group. Animals were kept in normal laboratory conditions of temperature $23 \pm 1^{\circ} \mathrm{C}$ and ambient humidity $55 \pm 5 \%$. Lights were maintained on an artificial $12 \mathrm{~h}$ light-dark cycle. All mice were weighed weekly during 6 weeks of experimental period. Mice were fed with high fat diet containing cholesterol, cholic acid, peanut oil and normal laboratory diet for 6 weeks. Test compound 1, test compound 2 and test compound 3 was mixed with high-fat diet (HFD) and the composition of the test compounds was 10mg/ kg. Group I received Normal laboratory diet, Group II received high fat diet, Group III received standard drug (Atorvastatin in this study) along with high fat diet, Group IV received test compound 1 along received with high fat diet, Group V received diet test compound 2 along with high fat diet and Group VI received test compound 3 along with high fat diet.

\subsubsection{Body weight}

Weights of the mice were taken after every week. Every group showed increase in weight Table 4.1 shows the weight of the animals in all six cages, each containing six mice at the start of experiment (zero week). These animals have received lab diet, high fat diet, standard drug, test compound 1 , test compound 2 and test compound 3 respectively.The average weight of the animals receiving lab diet was $22.2 \mathrm{~g}$,the average weight of the animals receiving high fat diet was $21.9 \mathrm{~g}$, the average weight of the animals receiving standard drug ( atorvastatin in our study) was $22.36 \mathrm{~g}$, the average weight of the animals receiving test compound 1 was 22.43 , the average weight of the animals receiving test compound 2 was $21.13 \mathrm{~g}$ and the average weight of the animals receiving test compound 3 was $20.81 \mathrm{~g}$.

\begin{tabular}{|c|c|c|c|c|c|c|}
\hline \multicolumn{7}{|c|}{$\begin{array}{l}\text { Weight of animals at the start of experiment (g) } \\
\text { (zero week) }\end{array}$} \\
\hline & Lab diet & High fat diet & Standard & Test 1 & Test 2 & Test 3 \\
\hline 1 & 22.5 & 19.3 & 22.4 & 23.9 & 26.9 & 22.9 \\
\hline 2 & 21.9 & 23.6 & 25.4 & 24.4 & 21.9 & 28 \\
\hline 3 & 22.1 & 23.2 & 24.1 & 23.1 & 13.9 & 19.1 \\
\hline 4 & 23.8 & 22.9 & 19.5 & 20.3 & 20.6 & 16.3 \\
\hline 5 & 24.5 & 20.7 & 20.9 & 20.5 & 18 & 21.3 \\
\hline 6 & 18.4 & 21.9 & 21.9 & 22.4 & 25.5 & 17.3 \\
\hline Total & 133.2 & 131.4 & 134.2 & 134.6 & 126.8 & 124.9 \\
\hline Average & 22.2 & 21.9 & 22.36 & 22.43 & 21.13 & 20.81 \\
\hline
\end{tabular}

Table 4.2 shows the weight of the animals after 1 week. The average weight of the animals receiving lab diet was $22.85 \mathrm{~g}$, the average weight of the animals receiving high fat diet was $22.98 \mathrm{~g}$, the average weight of the animals receiving standard drug (Atorvastatin in this study) was $22.66 \mathrm{~g}$, the average weight of the animals receiving test compound 1 was $23.25 \mathrm{~g}$, the average weight of the animals receiving test compound 2 was $21.65 \mathrm{~g}$ and the average weight of the animals receiving test compound 3 was $21.01 \mathrm{~g}$ The increases in weight of the animals have been shown after first week as compared to zero week.

Table 4.2 Table representing weights of the animals after first week

\begin{tabular}{|ccccccc|}
\hline \multicolumn{7}{c|}{ Weight of animals after first week (g) } \\
\hline & Lab diet & High fat diet & Standard & Test 1 & Test 2 & Test 3 \\
\hline 1 & 23.1 & 22.4 & 22.6 & 21.6 & 27.2 & 23.1 \\
2 & 21.9 & 28.5 & 25.7 & 25.3 & 22.9 & 28.2 \\
3 & 27.5 & 23.2 & 24.3 & 23.1 & 14.2 & 19.2 \\
4 & 21.2 & 20.2 & 19.8 & 20.8 & 21.2 & 18.6 \\
5 & 25 & 22.4 & 21.2 & 26.7 & 18.2 & 21.6 \\
6 & 18.4 & 21.2 & 22.4 & 22 & 26.2 & 17.4 \\
Total & 137.1 & 137.9 & 136 & 139.5 & 129.9 & 128.1 \\
\hline Average & 22.85 & 22.98 & 22.66 & 23.25 & 21.65 & 21.01 \\
\hline
\end{tabular}

weight of the animals

receiving lab diet was $25.33 \mathrm{~g}$, the average weight of the animals receiving high fat diet was

$28.5 \mathrm{~g}$, the average weight of the animals receiving standard drug (Atorvastatin in this study) was

$24.96 \mathrm{~g}$, the average weight of the animals receiving test compound 1 was $28.75 \mathrm{~g}$, the average

weight of the animals receiving test compound 2 was $27.36 \mathrm{~g}$ and the average weight of the

animals receiving test compound 3 was $25.6 \mathrm{~g}$. The increases in weight of the animals have been

shown after second week as compared to zero and first week.

Table 4.3 Table representing weights of the animals after second week

\begin{tabular}{|ccccccc|}
\hline \multicolumn{7}{|c|}{ Weights of animals after two weeks (g) } \\
\hline & Lab diet & High fat diet & standard & Test 1 & Test 2 & Test 3 \\
\hline 1 & 32.7 & 29.5 & 24.3 & 26.9 & 31.5 & 25 \\
2 & 21 & 25.7 & 27 & 29.6 & 33.2 & 30 \\
3 & 26.9 & 31.8 & 26.9 & 25.5 & 27.5 & 26.3 \\
4 & 19.2 & 27.9 & 21.8 & 30.2 & 23.7 & 25.1 \\
5 & 27.4 & 29.8 & 24 & 31.3 & 29.8 & 27.6 \\
6 & 24.8 & 26.3 & 25.8 & 29 & 18.5 & 20 \\
Total & 152 & 171 & 149.8 & 172.5 & 164.2 & 154 \\
\hline Average & 25.33 & 28.5 & 24.96 & 28.75 & 27.36 & 25.6 \\
\hline
\end{tabular}

Table 4.4 shows the weight of the animals after third week. The average weight of the animals receiving lab diet was $26.91 \mathrm{~g}$, the average weight of the animals receiving high fat diet was $29.23 \mathrm{~g}$, the average weight of the animals receiving standard drug (Atorvastatin in this study) was $26.45 \mathrm{~g}$, the average weight of the animals receiving test compound 1 was $29.81 \mathrm{~g}$, the average weight of the animals receiving test compound 2

22 was $28.34 \mathrm{~g}$ and the average weight of the animals receiving test compound 3 was $27.03 \mathrm{~g}$. The increases in weight of the animals have been shown after third week as compared to zero, first and second week.

Table 4.4 Table representing weights of the animals after third week

\begin{tabular}{|ccccccc|}
\hline \multicolumn{7}{|c|}{ Weights of animals after third week (g) } \\
\hline & Lab diet & Fat diet & standard & Test 1 & Test 2 & Test 3 \\
\hline 1 & 33.3 & 29.4 & 26.7 & 29 & 31.9 & 27.5 \\
2 & 22.7 & 27.9 & 28.8 & 29.8 & 33.3 & 30.3 \\
3 & 29.1 & 30.9 & 27.6 & 27.7 & 27.8 & 27.4 \\
4 & 22.1 & 29.1 & 23.4 & 29.4 & 27.3 & 27.2 \\
5 & 28.5 & 30.2 & 25.6 & 32.6 & 29.75 & 27.7 \\
6 & 25.8 & 27.6 & 26.6 & 30.4 & 20 & 22.1 \\
Total & 161.5 & 175.1 & 158.7 & 178.9 & 170.05 & 162.2 \\
\hline Average & 26.91 & 29.23 & 26.45 & 29.81 & 28.34 & 27.03 \\
\hline
\end{tabular}

Table 4.5 shows the weight of the animals after fourth week. The average weight of the animals

receiving lab diet was $28.58 \mathrm{~g}$, the average weight of the animals receiving high fat diet was

$30.03 \mathrm{~g}$, the average weight of the animals receiving standard drug (Atorvastatin in this study) was $28 \mathrm{~g}$, the average weight of the animals receiving test compound 1 was $31.1 \mathrm{~g}$, the average weight of the animals receiving test compound 2 was $29.46 \mathrm{~g}$ and the average weight of the animals receiving test compound 3 was $28.65 \mathrm{~g}$. The increases in weight of the animals have been shown after fourth week as compared to zero, first, second and third week.

Table 4.5 Table representing weights of the animals after fourth week

\begin{tabular}{|crrrrrr|}
\hline \multicolumn{7}{|c|}{ Weights of animals after fourth weeks (g) } \\
\hline Lab diet & Fat diet & standard & Test 1 & Test 2 & Test 3 \\
\hline 1 & 33.9 & 27.3 & 27.4 & 31.1 & 33.1 & 31 \\
2 & 24.5 & 30 & 29.3 & 31.1 & 34.7 & 30.7 \\
3 & 31.4 & 34.3 & 29.9 & 30 & 30.6 & 28.65 \\
4 & 25.1 & 30.2 & 25.6 & 28.6 & 27.4 & 29.4 \\
5 & 29.7 & 30.4 & 27.4 & 34 & 29.7 & 27.9 \\
6 & 26.9 & 28 & 28.4 & 31.8 & 21.3 & 24.3 \\
Total & 171.5 & 180.2 & 168 & 186.6 & 176.8 & 171.95 \\
\hline Average & 28.58 & 30.03 & 28 & 31.1 & 29.46 & 28.65 \\
\hline
\end{tabular}


Table 4.6 shows the weight of the animals after fifth week. The average weight of the animals receiving lab diet was 30.69g, the average weight of the animals receiving high fat diet was $32.95 \mathrm{~g}$, the average weight of the animals receiving standard drug (Atorvastatin in this study) was $28.5 \mathrm{~g}$, the average weight of the animals receiving test compound 1 was $32.26 \mathrm{~g}$, the average weight of the animals receiving test compound 2 was $30.54 \mathrm{~g}$ and the average weight of the animals receiving test compound 3 was $30.14 \mathrm{~g}$. The increases in weight of the animals have been shown after fifth week as compared to zero, first, second, third, fourth and fifth week.

Table 4.6 Table representing weights of the animals after fifth week

\begin{tabular}{|ccccccc|}
\hline \multicolumn{7}{|c|}{ Weights of animals after fifth week (g) } \\
\hline & Lab test & Fat diet & Standard & Test 1 & Test 2 & Test 3 \\
\hline 1 & 34.5 & 25 & 28.9 & 33.2 & 33.9 & 34 \\
2 & 29.2 & 32 & 29.8 & 31.8 & 35.5 & 31.1 \\
3 & 33.7 & 34.1 & 27.6 & 32.3 & 32.2 & 29.8 \\
4 & 28.05 & 35 & 26.4 & 27.8 & 29.3 & 31.5 \\
5 & 30.8 & 35.6 & 29.6 & 35.3 & 29.65 & 28.05 \\
6 & 27.9 & 36 & 28.7 & 33.2 & 22.7 & 26.4 \\
Total & 184.15 & 197.7 & 171 & 193.6 & 183.25 & 180.85 \\
\hline Average & 30.69 & 32.95 & 28.5 & 32.26 & 30.54 & 30.14 \\
\hline
\end{tabular}

Table 4.7 shows the weight of the animals after sixth week. The average weight of the animals receiving lab diet was $31.85 \mathrm{~g}$, the average weight of the animals receiving high fat diet was $33.85 \mathrm{~g}$, the average weight of the animals receiving standard drug (Atorvastatin in this study) was $29.76 \mathrm{~g}$, the average weight of the animals receiving test compound 1 was $33.46 \mathrm{~g}$, the average weight of the animals receiving test compound 2 was $31.65 \mathrm{~g}$ and the average weight of the animals receiving test compound 3 was $31.66 \mathrm{~g}$. The increases in weight of the animals have been shown after sixth week as compared to zero, first, second, third, fourth, and fifth week.

Table 4.7 Table representing weights of the animals after sixth week

\begin{tabular}{|ccccccc|}
\hline \multicolumn{7}{c|}{ Weights of animals after sixth week(g) } \\
\hline & Lab test & Fat diet & standard & Test 1 & Test 2 & Test 3 \\
\hline 1 & 35.1 & 31 & 29.8 & 35.3 & 34.7 & 37 \\
2 & 28 & 31.6 & 29.9 & 32.6 & 36.3 & 31.5 \\
3 & 36 & 33.2 & 29.4 & 34.6 & 33.8 & 31 \\
4 & 31 & 35.2 & 29.9 & 27 & 31.2 & 33.7 \\
5 & 32 & 36 & 29.8 & 36.7 & 29.6 & 28.2 \\
6 & 29 & 36.1 & 29.8 & 34.6 & 24.2 & 28.6 \\
Total & 191.1 & 203.1 & 178.6 & 200.8 & 189.8 & 190 \\
\hline Average & 31.85 & 33.85 & 29.76 & 33.46 & 31.65 & 31.66 \\
\hline
\end{tabular}

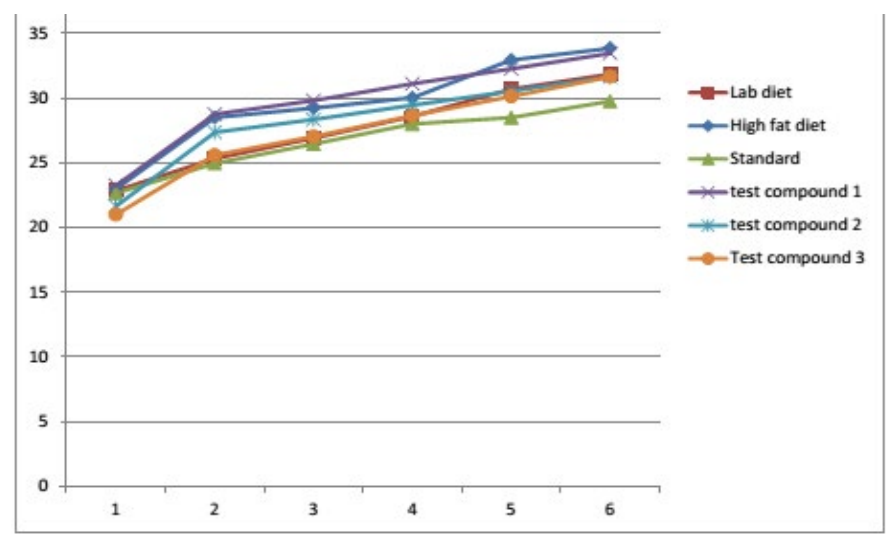

Fig 4.1: line graph representing average weight of animals of different groups

There is a steady increase in the average weight of the animals receiving lab diet from week 1 to week 6 as sown in fig.4.2. In case of high fat diet receiving animals there is a rapid increase in the average weight of animals from week 1 to week 2 , then steady increase is seen from week 2 to week 6 as shown in fig.4.3. Steady increase is a seen in animals receiving standard drug (Atorvastatin in our study) from week 1 to week 6 as shown in fig.4.4. Abrupt increase in average weight of animals is also seen in group receiving test compound 1, 2 and 3 from week 1 to week 2 then consistent increase of average weight is seen in 2 to week 6 as shown in fig. 4.5, 4.6 and 4.7 respectively.

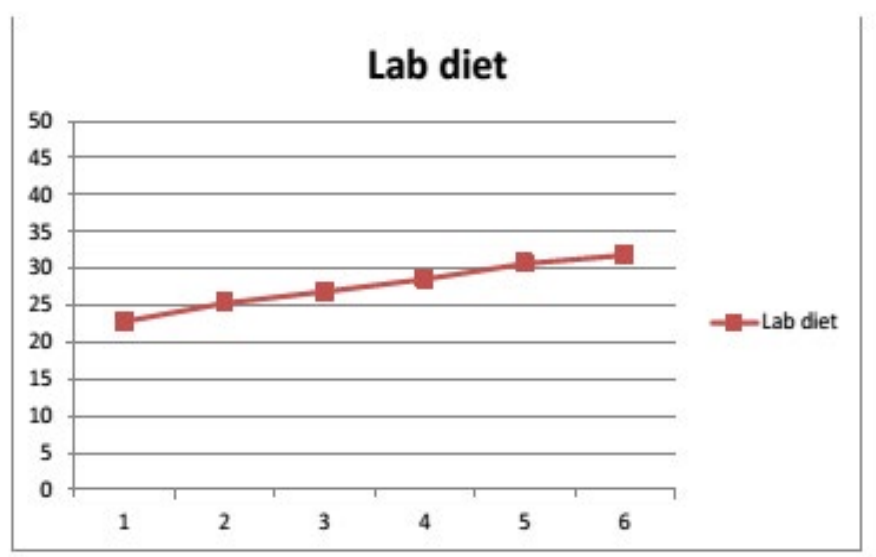

Fig.4.2 line graph representing body weight of animals receiving lab diet

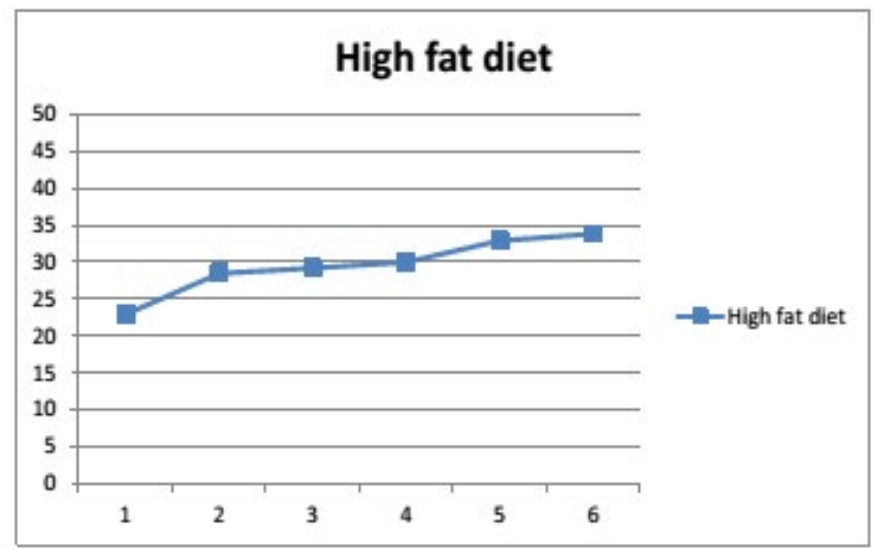

Fig.4.3 line graph representing body weight of animals receiving high fat diet

\section{Standard}

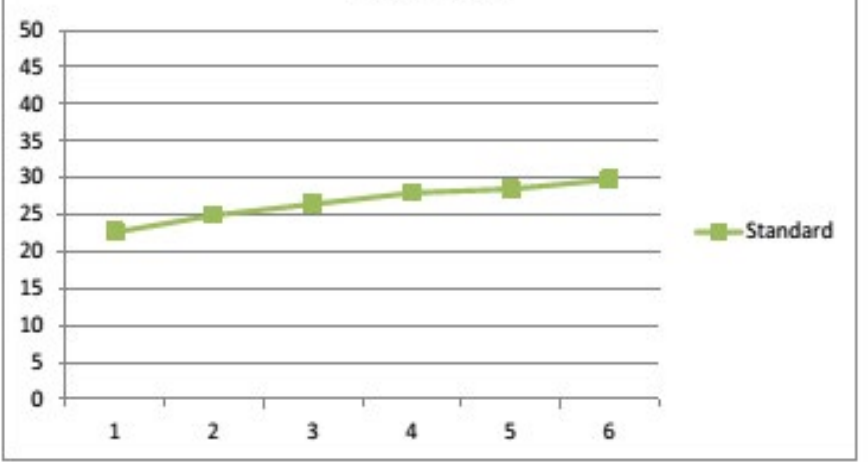

Fig.4.4 line graph representing body weight of animals receiving standard

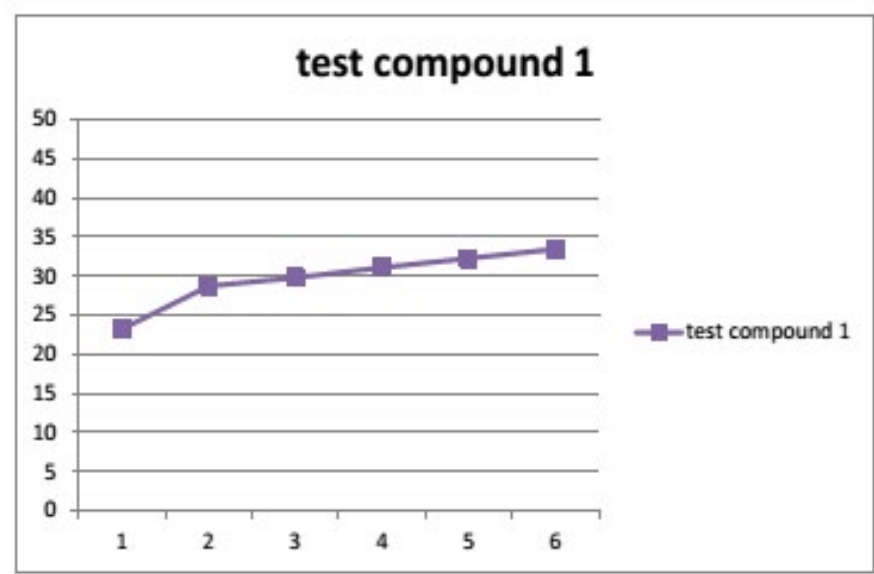


Fig.4.5 line graph representing body weight of animals receiving test compound 1

\section{test compound 2}

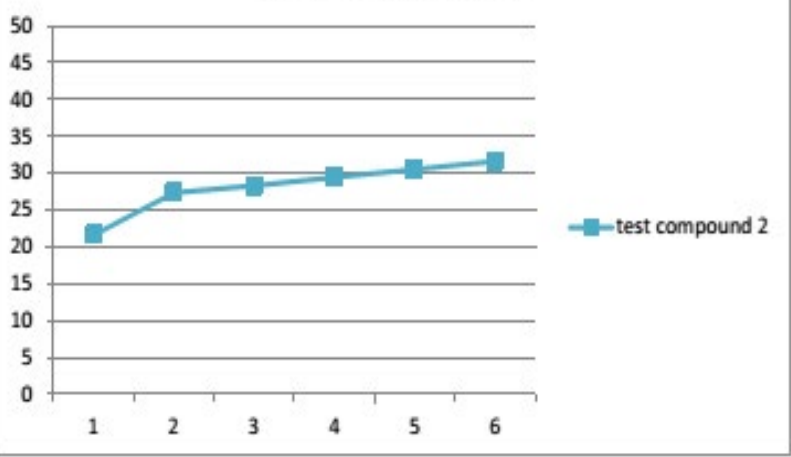

Fig.4.6 line graph representing body weight of animals receiving test compound 2

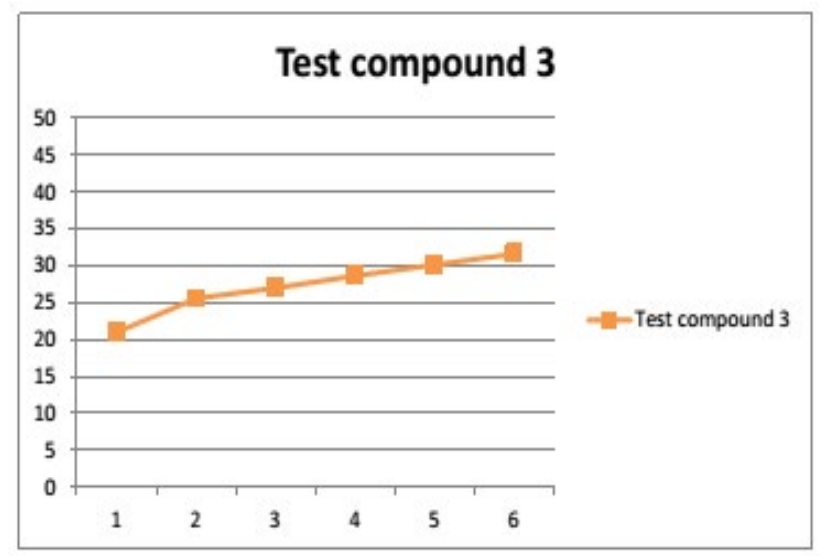

Fig.4.7 line graph representing body weight of animals receiving test compound 3

\subsubsection{Increase in percentage body weight}

The average body weight of all experimental animals was increased in corresponding increase in experimental schedule as shown in table 4.8. At the end of 6 weeks the HFD group showed the highest percent increase in average body weight which was found to be $54.56 \%$. Test compound 1 showed $49.17 \%$ increase in average body weight, test compound 2 showed $49.78 \%$ increase in average body weight and test compound 3 showed $52.13 \%$ increase in average body weight. Test compounds nearly similar patterns in percent increase of body weight as that of HFD group. The group receiving standard drug showed $33.09 \%$ increase in average body weight as shown in fig.4.8.

Table 4.8 Table representing average weights of the animals of different groups from week 1 to week $6(\mathrm{~g})$

\begin{tabular}{|c|c|c|c|c|c|c|}
\hline Week & Lab diet & High fat diet & Standard & test compound 1 & test compound 2 & Test compound 3 \\
\hline 0 & 22.2 & 21.9 & 22.36 & 22.43 & 21.13 & 20.81 \\
\hline 1 & 22.85 & 22.98 & 22.66 & 23.25 & 21.65 & 21.01 \\
\hline 2 & 25.33 & 28.5 & 24.96 & 28.75 & 27.36 & 25.6 \\
\hline 3 & 26.91 & 29.23 & 26.45 & 29.81 & 28.34 & 27.03 \\
\hline 4 & 28.58 & 30.03 & 28 & 31.1 & 29.46 & 28.65 \\
\hline 5 & 30.69 & 32.95 & 28.5 & 32.26 & 30.54 & 30.14 \\
\hline 6 & 31.85 & 33.85 & 29.76 & 33.46 & 31.65 & 31.66 \\
\hline
\end{tabular}

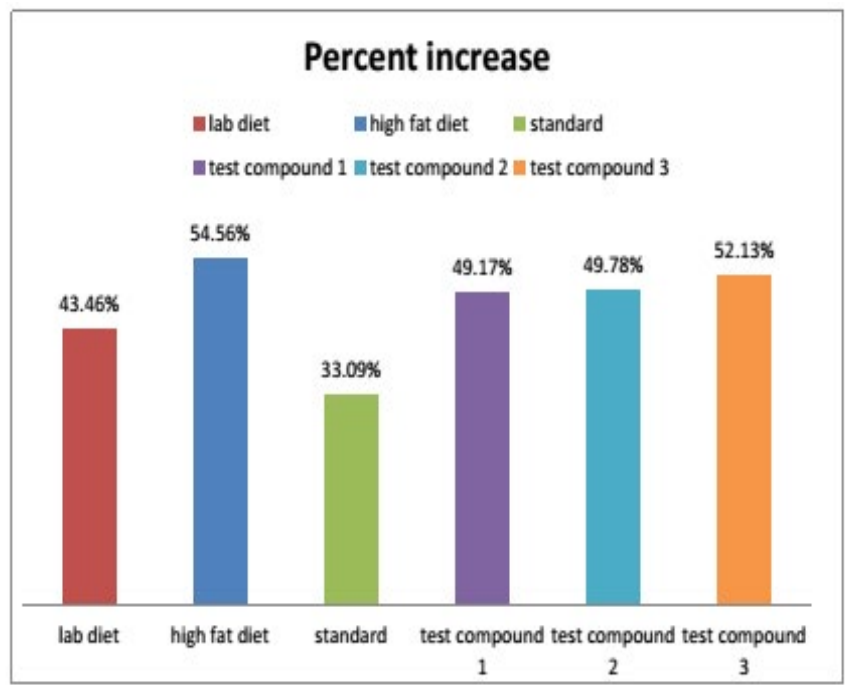

Fig 4.8 Bar graph showing percent increase in the average weight of the animals of different group. These results suggested that the newly semi synthesized phenolic compounds show insignificant results when compared with the positive and negative control.

\subsubsection{Liver weight}

Liver weight of the mice was determined after supplementation of high fat diet with test compound 1, test compound 2, test compound 3 and standard drug (Atorvastatin in this study) for 6 weeks as shown in table 4.9. Average liver weight of the mice group fed with high fat diet $(1.23 \mathrm{~g})$ was significantly similar as compared to that of test compound $1(1.13 \mathrm{~g})$, test compound $2(1.17 \mathrm{~g})$ and test compound $3(1.21 \mathrm{~g})$. There was an increase in the liver weight of the experimental animals group supplemented with high fat diet. Standard drug (Atorvastatin in this study) supplemented mice $(1.03 \mathrm{~g})$ showed the lowest liver weight as compared to experimental groups supplemented with test compound 1 , test compound 2 and test compound 3 as shown in fig. 4.9

Table 4.9 Table representing average liver weight of experimental animals at the end of sixth week

\begin{tabular}{|c|c|}
\hline Group & Liver weight (g) \\
\hline Lab diet & 0.9 \\
\hline High fat diet & 1.23 \\
\hline Standard & 1.03 \\
\hline Test compound 1 & 1.13 \\
\hline Test compound 2 & 1.17 \\
\hline Test compound 3 & 1.21 \\
\hline
\end{tabular}

\section{Liver weight}

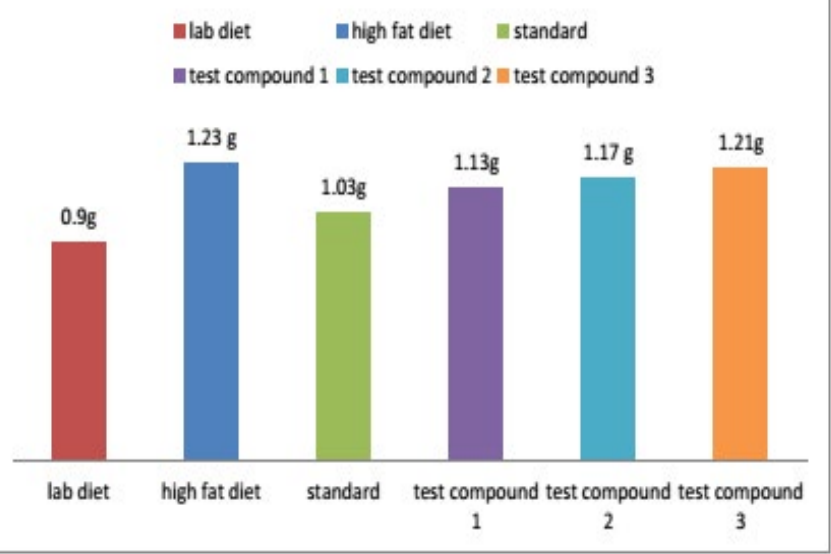


Fig. 4.9 Bar graph showing average liver weight of the animals of different groups

\subsubsection{Plasma lipid profile}

Plasma lipid profile that includes cholesterol, triglycerides, high-density lipoprotein, and low-density lipoprotein was evaluated as showed in table 4.10. Supplementation of the high fat diet (HFD) significantly increased total cholesterol, HDL and LDL compared with lab diet fed mice. Standard drug showed decreased total cholesterol, triglycerides, LDL and increased HDL as compared to HFD group as the activity of the standard drug Atorvastatin is proven. Test compound 1 , test compound 2 and test compound 3 showed nearly similar results of lipid profile as that of high fat diet fed mice as shown in fig.4.10.

Table 4.10 representing plasma lipid profile of mice fed high fat diet with standard, test compound 1 , test compound 2 and test compound $3(\mathrm{mg} / \mathrm{dl})$

\begin{tabular}{|c|c|c|c|c|}
\hline Groups & $\begin{array}{c}\text { Total } \\
\text { cholesterol }\end{array}$ & Triglycerides & $\begin{array}{c}\text { High-density } \\
\text { lipoprotein } \\
\text { (HDL) }\end{array}$ & $\begin{array}{c}\text { Low-density } \\
\text { lipoprotein } \\
\text { (LDL) }\end{array}$ \\
\hline Lab diet & 92.8 & 86.6 & 33.4 & 41.6 \\
\hline High fat diet & 386.2 & 162 & 36.2 & 317.4 \\
\hline Standard & 165.4 & 114.4 & 49 & 89 \\
\hline Test compound 1 & 369.7 & 160.8 & 32.6 & 309.1 \\
\hline Test compound 2 & 375.1 & 162.8 & 34.4 & 311.3 \\
\hline Test compound 3 & 377.4 & 159.9 & 30.4 & 313.4 \\
\hline
\end{tabular}

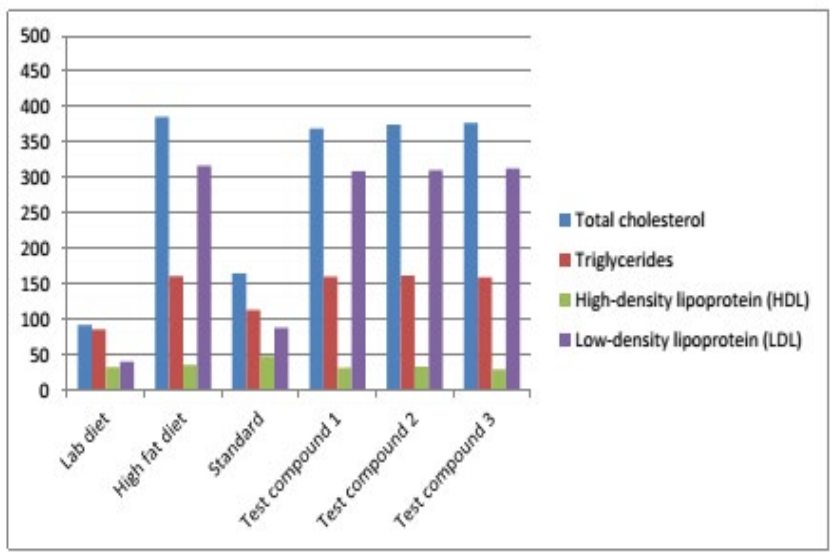

Fig.4.10 Bar graph showing plasma lipid profile of different experimental groups

\section{Conclusion}

In the present study antihyperlipideic activity was performed in high fat diet induced hyperlipidemic mice models. It was indicated that there is insignificant diffrence in the average body weight, liver weight and plasma lipid profile of the phenolic test compound 1, test compound 2 and test compound 3 as compared with the standard drug (Atorvastatin in this study). Although the antihyperlipidemic activity of these phenolic compounds is not strong but literature showed that phenolic compounds show cardiac potential so that these compounds should be evaluated for their cardiovascular potential like cyclooxygenase inhibition, antithrombotic and vasodilator activity.

\section{References}

1. Brai, B. I. C., A. A. Odetola, and P. U. Agomo. "Effects of Persea americana leaf extracts on body weight and liver lipids in rats fed hyperlipidaemic diet."African

journal of Biotechnology 6.8 (2007).

2. Kurogi, Yasuhisa, et al. "Synthesis and hypolipidemic activities of novel 2-[4- [(diethoxyphosphoryl) methyl] phenyl] quinazolines and $4(3 \mathrm{H})$ quinazolinones." Journal of medicinal chemistry 39.7 (1996): 1433-1437.

3. Raederstorff, Daniel G., et al. "Effect of EGCG on lipid absorption and plasma lipid levels in rats." The Journal of nutritional biochemistry 14.6 (2003): 326-332.

4. Grundy SM, Cleeman JI, Merz CN, et al. Implications of recent clinical trials for the National Cholesterol Education Program Adult Treatment Panel III guidelines. Circulation 2004; 110:227.

5. Gardner CD, Lawson LD, Block E, et al. Effect of raw garlic vs commercial garlic supplements on plasma lipid concentrations in adults with moderate hypercholesterolemia: a randomized clinical trial. Arch Intern Med 2007; 167:346.

6. Hsu, Chin-Lin, and Gow-Chin Yen. "Phenolic compounds: evidence for inhibitory effects against obesity and their underlying molecular signaling mechanisms." Molecular nutrition \& food research 52.1 (2008): 53-61.

7. Durendic Brenesel, Maja, et al. "Antihyperlipidemic, antioxidant and weightlowering effects of "Vitalplant"." Open Life Sciences 10.1 (2015).

8. Sharma, S. "a study of anti-hyperlipidemic activity of marketed formulations of terminalia arjuna powder using experimental animal model." Journal of Biomedical and Pharmaceutical Research 4.1 (2015).

9. Kooti, Wesam, et al. "The effects of hydro-alcoholic extract of celery on lipid profile of rats fed a high fat diet." Advances in Environmental Biology (2014): 325-331.

10. Akdim, Fatima, et al. "Effect of mipomersen, an apolipoprotein B synthesis inhibitor, on low-density lipoprotein cholesterol in patients with familial hypercholesterolemia." The American journal of cardiology 105.10 (2010): 1413-1419.

11. Rachh, P. R., et al. "Antihyperlipidemic activity of Gymenma sylvestre R. Br. leaf extract on rats fed with high cholesterol diet." IJP-International Journal of Pharmacology 6.2 (2010): 138-141.

12. Mokale, Santosh N.,Priyanka T. Sanap, and Devanand B. Shinde. "Synthesis and hypolipidemic activity of novel 2-(4-(2-substituted aminothiazole-4-yl) phenoxy) acetic acid derivatives." European journal of medicinal chemistry 45.7 (2010): 3096-3100. 